\title{
Urine Magnesium Measurement
}

National Cancer Institute

\section{Source}

National Cancer Institute. Urine Magnesium Measurement. NCI Thesaurus. Code C61049.

A quantitative measurement of the total amount of magnesium present in a sample of urine. 